\title{
Do dolphins rehearse show-stimuli when at rest? Delayed matching of auditory memory
}

\author{
Dorothee Kremers $^{1 *}$, Margarita Briseño Jaramillo ${ }^{1}$, Martin Böye ${ }^{2}$, Alban Lemasson $^{1,3 \dagger}$ and \\ Martine Hausberger ${ }^{1 t}$
}

${ }^{1}$ Ethologie Animale et Humaine, Université de Rennes 1, Paimpont, France

${ }^{2}$ Département Scientifique et Pédagogique, Planète Sauvage, Port Saint-Père, France

${ }^{3}$ Institut Universitaire de France, Paris, France

Edited by:

Patrizia D'Ettorre, University of Paris

13, France

Reviewed by:

Patrizia D'Ettorre, University of Paris

13, France

Francesco Bonadonna, CNRS, France

Dalila Bovet, Université Paris Ouest

Nanterre La Défense, France

${ }^{*}$ Correspondence:

Dorothee Kremers, Ethologie animale et humaine, Université de Rennes 1, Station Biologique, 35380 Paimpont,

France.

e-mail: dorothee.kremers@

univ-rennes 1.fr

${ }^{+}$Alban Lemasson and

Martine Hausberger have contributed equally to this work.
The mechanisms underlying vocal mimicry in animals remain an open question. Delphinidae are able to copy sounds from their environment that are not produced by conspecifics. Usually, these mimicries occur associated with the context in which they were learned. No reports address the question of separation between auditory memory formation and spontaneous vocal copying although the sensory and motor phases of vocal learning are separated in a variety of songbirds. Here we show that captive bottlenose dolphins produce, during their nighttime resting periods, non-dolphin sounds that they heard during performance shows. Generally, in the middle of the night, these animals produced vocal copies of whale sounds that had been broadcast during daily public shows. As their life history was fully known, we know that these captive dolphins had never had the opportunity to hear whale sounds before then. Moreover, recordings made before the whale sounds started being broadcast revealed that they had never emitted such sounds before. This is to our knowledge the first evidence for a separation between formation of auditory memories and the process of learning to produce calls that match these memories in a marine mammal. One hypothesis is that dolphins may rehearse some special events heard during the daytime and that they then express vocally what could be conceived as a more global memory. These results open the way for broader views on how animals might rehearse life events while resting or maybe dreaming.

Keywords: auditory memory processes, interspecific vocal copying, sensory-motor-phases separation, cetacean acoustic plasticity

\section{INTRODUCTION}

Dolphins have the ability to copy sounds from their environment other than those produced by conspecifics, like orangutans or elephants, under captive conditions when mimicries are associated with salient events, such as training or shows (Richards et al., 1984; Poole et al., 2005; Wich et al., 2009; Kelley and Healy, 2011). Interspecific copying by cetaceans has been reported under field conditions, seemingly in association with agonistic interactions (May-Collado, 2010), social separation (Foote et al., 2006), or other emotionally salient contexts. Earlier anecdotic reports concerning birds mention that vocal mimicry can in some cases emerge and be kept in memory in association with particularly salient events (Armstrong, 1960; Frith and Frith, 2004), one famous example being Lorenz's (1952) free-living, tame hooded crow (cited in Armstrong, 1960) coming back with a broken foot and a never before heard sentence: "Got'im in t'bloomin'trap" (in "Austrian street language").

Examples of separation between auditory memory formation and vocal copying are common in a variety of songbird (e.g., Thorpe, 1961) and parrot (Pepperberg, 1997) species, when the sensory and motor phases of vocal learning are separated. Songbirds can produce vocal copies totally independently of the context in which they were learned (Hausberger et al., 1991). Similarly, dolphins are capable of associating given sounds with an object or context (Richards et al., 1984; Reiss and McCowan, 1993). Hooper et al. (2006) demonstrated that dolphins' imitations can be enhanced by associating sounds with salient events. Here we questioned whether dolphins would produce copies of whale sounds associated with daily shows, a salient event for them.

One intriguing finding is the activation of the same neurons during sleep as while awake in songbirds, which suggests a rehearsal of song during sleep (Dave and Margoliash, 2000). Actually, memories of salient events can lead to rehearsal in the form of dreams during sleep both in humans and animals (Cipolli et al., 2004). Animals that have undergone a lesion of their locus coeruleus present motor expressions of their dreams, e.g., hunting in sleeping cats (Jouvet, 1979). Vocalizations during sleep are commonly reported, as for instance in horses (Ruckebusch et al., 1970). Speech produced by humans during sleep corresponds to their dream contents (Jouvet, 1979). The quality of dreams depends on the type of sleep; more negative-emotional type dreaming occurs during REM (i.e., rapid eye movement) sleep (Stickgold et al., 2001), whereas during non-REM (or day) dreams, the episodic memory (memory of an event as a whole) is more involved (Stickgold et al., 2001; Vandekerckhove and Cluydts, 2010): an "offline model of the world" where events and social interactions are associated in a 
"vivid and multimodal simulation of real experience" (Revonsuo, 2000). Therefore we hypothesized that vocal copies could occur at night during resting or sleeping.

Here we describe the nocturnal production of vocal mimicries by captive bottlenose dolphins (Tursiops truncatus) of whale sounds that they only heard during daytime show periods (i.e., whale songs played back to the public through loudspeakers). Our results reveal that delayed production of auditory memories does occur in dolphins, one explanation being that they have a memory of sounds associated with salient events, which would then be produced during rehearsals.

\section{MATERIALS AND METHODS BACKGROUND}

\section{Study group and housing conditions}

Subject were five captive-born dolphins (two females, three males, from 5 to 25 years old) housed at the "Planète Sauvage" dolphinarium (France). They have been in this facility as a group since December 2008 and came from two dolphinarium belonging to the same company. In all, this facility covers over $2000 \mathrm{~m}^{2}$ water surface and contains $8500000 \mathrm{l}$ salt water cleaned with ozone (no chlorine). They were feed comprised variety of fish (herring, capelin, sprat, mackerel, and whiting) and squid. The daily ration of 5-10 kg per individual (depending on its size) was given several different times during feeding or training sessions. Training includes medical training (e.g., acceptance of inspection and palpation of all parts of the body or being touched by medical equipment) as well as training for public shows.

\section{Public shows}

The dolphins performed exercises during daily public shows (one to four per day, depending on the season). These educative shows were composed of a set of activities (each time performed in a different order so that the dolphins did not become bored) aiming to explain dolphins' biology and behavior to the public: demonstration of body features (dorsal and pectoral fins, fluke, blowhole), physical abilities (swimming at maximum speed, jumping), visual abilities (catching thrown balls), sounds (in-air vocalizations). During the shows, a trainer commented the different activities. From the 28 February 2009 on, a 21-min soundtrack was broadcast at the beginning of the shows (while the visitors came in and sat down), which included music, sea gulls' calls, dolphins' whistles (their own), and predominantly humpback whales' vocalizations. The playbacks of humpback whale sounds were only broadcast in the current facility and during the period of shows, in total for $\sim 2$ min (a 14-s sequence of five whale calls was repeated eight times during the 21-min music track), generally two to three times a day.

\section{Data collection}

The vocalizations were recorded between November 2008 and May 2009 for 9 days and 8 nights. The recordings were performed using a Nauta SS03-10 hydrophone connected to a Marantz PMD 670 recorder (sample rate: $44.1 \mathrm{kHz}$; resolution: $16 \mathrm{bit}$ ) without the possibility to identify emitters. Observations complied with the current French laws governing animal research.

\section{DISCRIMINANT FUNCTION ANALYSIS}

We compared dolphins' vocalizations with the broadcast whale sounds by measuring frequency and time parameters using Raven Pro 1.3. Measurements were then analyzed using a stepwise Discriminant function analysis (in SPSS 11.5). Only high quality (i.e., low background noise) "whale-like" productions (WLPs) and randomly chosen whistles were used.

\section{HUMAN PLAYBACK EXPERIMENT}

To evaluate dolphin-whale similarities five WLPs (at normal speed and half speed) and five whale sounds were broadcast to 20 human subjects (male and female master and Ph.D. students and scientists working in behavioral biology) that were blind to the study and unfamiliar with cetacean vocalizations. Again only high quality whistles and WLPs (i.e., low background noise) were chosen from our own recordings. Three humpback whale calls from the Planète Sauvage broadcast were used as well as two additional calls from free-ranging individuals (www.whalesong.net) to see if these calls differed. Dolphins' whistles, WLPs, and whale calls were chosen so that they all had approximately the same duration in order to avoid classification based on the length of the sound. Since the WLPs were said to sound like "accelerated" versions of the real whale sounds, we also tested slowed down (factor of 0.5 ) versions of the WLPs (see Audio S1-S4 in Supplementary Material). To ensure that dolphins' WLPs were not classified as different from dolphins' whistles because of this manipulation, the whistles were played back both at normal speed and slowed down. The sounds were equalized $(71.8 \mathrm{~dB})$ in sound level using ANA software and a DVM401 Voltcraft decibel meter. A set of five whale sounds, 10 dolphin whistles (five normal speed/five half speed), and 10 dolphin WLPs (five normal speed/five half speed) was randomly broadcast to each subject. After listening to an example of a whale and a dolphin sounds (not included in the testing set), subjects were asked to classify the sounds as a "whale" or "dolphin" sound. Human classifications were compared using a Wilcoxon test with Bonferroni corrections $\left(P_{\text {corrected }}=0.003\right)$.

\section{RESULTS}

\section{GENERAL RESULTS}

Recordings performed between November 2008 and February 2009 ( $>80 \mathrm{~h}$ ) yielded 2370 vocalizations ( 2182 whistles, 188 burstpulsed) from five dolphins. After the broadcast of the soundtrack started, recordings were made between February and May 2009 $(40 \mathrm{~h})$ yielding 876 vocalizations (218 during the day; 658 at night, i.e., 10 p.m. to 06 a.m.). Whereas the vocalizations during the day did not change after the broadcast started, atypical sounds were recorded during the night; these sounds had never been recorded before the broadcast had started. The first atypical sound was recorded after 87 playbacks of the show tape (after 34 days with broadcast). Most remarkable was that 20 of the 25 atypical sounds were recorded between 1 and 3 a.m. (Table 1 ), which is during early night when the animals were resting, or even potentially sleeping. The five remaining sounds were recorded early morning (6 to 9 a.m.) while the dolphins were also resting. None of these atypical sounds was ever recorded during a show, which would suggest immediate mimicry, or during periods of intense activity. Comparisons with the past and present acoustic environment of these 
animals and these vocalizations revealed that the only close structure was the whale sounds broadcast during the public shows. The life history of these animals was fully known (same company) and these dolphins had had no opportunity to hear such whale sounds at any stage.

\section{ACOUSTIC ANALYSIS}

These atypical vocalizations clearly stood out from the range of classical descriptions of dolphin whistles' characteristics (Table 1), being characterized by a lower pitch and a larger number of harmonics (Figure 1). The dolphins also produced other low-pitched, namely burst-pulsed vocalizations (Figure 1Ab), which are not unusual in the dolphins' vocal repertoire (dos Santos et al., 1995; Connor and Smolker, 1996; van der Woude, 2009). Nevertheless, these WLPs (Figure 1Ba) clearly differed from their burst-pulsed vocalizations in terms of noisiness and frequency modulation patterns; they also lasted much longer and were higher pitched. To ensure that these productions were copies, sounds being broadcast

Table 1 | Acoustic parameters and recording times of dolphins' and humpback whales' vocalizations.

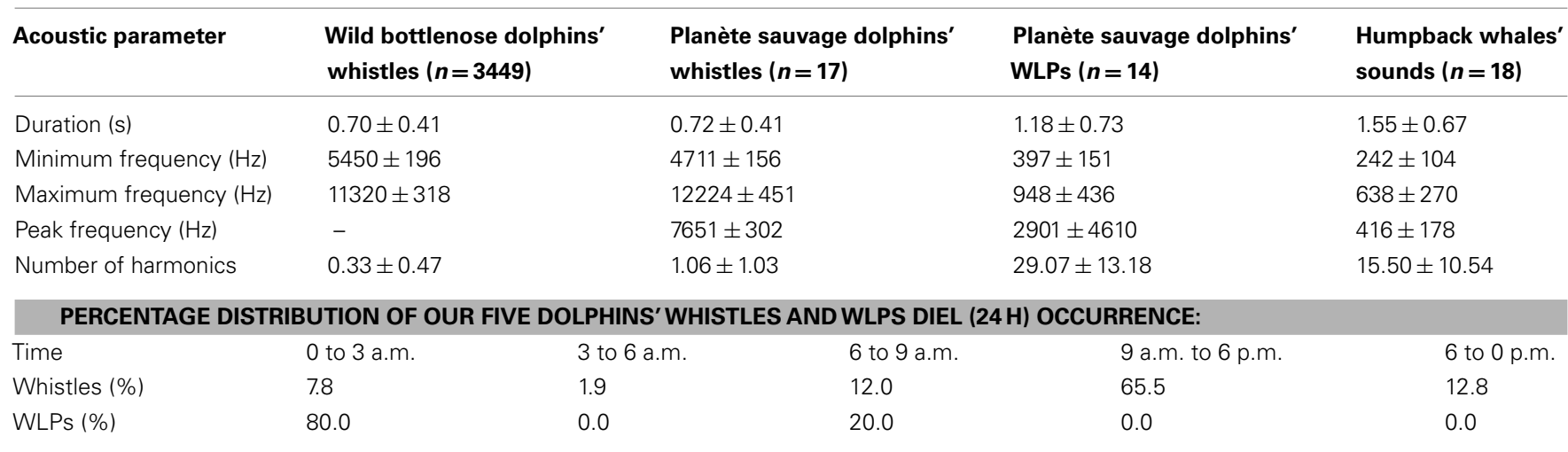

Data for wild bottlenose dolphins were taken from Ding et al. (1995) as an example; humpback whale sounds were taken from The Ocean Mammal Institute (http://www.oceanmammalinst.com/songs.htm/) andThe Whale song Project (http://www.whalesong.net/index.php/the-whalesong-project/sounds/whale-songs). The Planète Sauvage dolphins' whistles were chosen randomly from our own recordings with the aim to match approximately the WLPS ("Whale-like" productions) sample size and humpback whale sounds. Acoustic measurements are given as mean $\pm S D$.

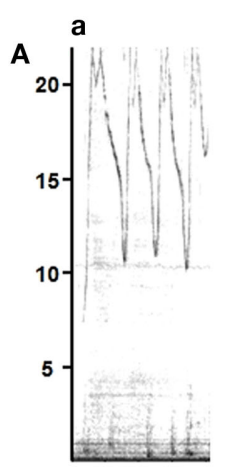

a

B

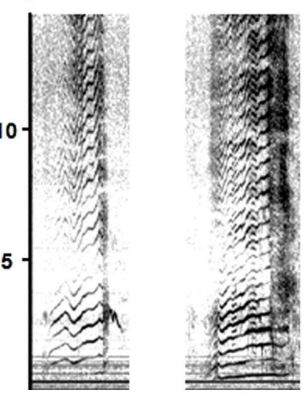

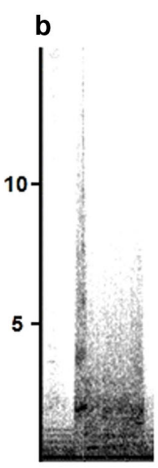

b

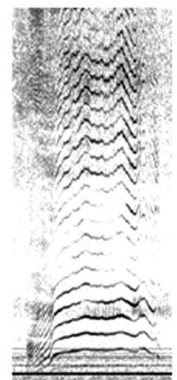

FIGURE 1 |A spectrogram of the Plantète Sauvage dolphins' (A) common vocal repertoire, (a) whistles and (b) burst-pulsed vocalizations, and (B) their atypical (a) whale-like productions (WLPs) and (b) the

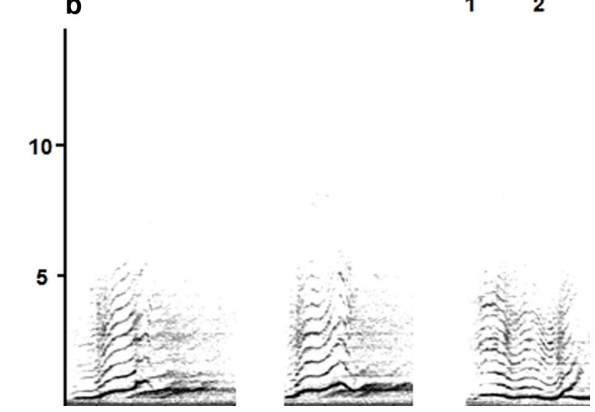

"model" humpback whales' sounds. FFT: (Aa) 1024; (Ab), (Ba), and (Bb) 2282. The time axes for all spectrograms have been standardized; but the (Aa) frequency axis has been extended. 
and the dolphins' WLPs were compared both in terms of measurements and by testing a naïve human audience (see Human Playback Experiment). A discriminant function analysis, based on temporal and frequency parameters, clearly separated the "ordinary" dolphin whistles from both WLPs and the "model" whale sounds, while the latter overlapped [Figure 2; percentage of correctly classified cases: dolphins' whistles 100\%, dolphins' WLPs $60.0 \%$ (40.0\% classified as "whale sounds"), humpback whales' sounds $88.9 \%$ (11.1\% classified as “dolphins' WLPs”)].

\section{HUMAN PLAYBACK EXPERIMENT}

Human evaluations confirmed these findings. After listening to an example of a humpback whale and a dolphin sound (humpback whale sound from The Ocean Mammal Institute; dolphin sound randomly chosen from our own recordings of this group), they were asked to classify the sounds as being produced by a whale or by a dolphin. While the model whale sounds and ordinary dolphin whistles were clearly identified as such (88-99\%), WLPs were often classified as being a whale sound, especially when slowed down (76\%; Figure 3; Wilcoxon test, $P \leq 0.000)$.

\section{DISCUSSION}

This study describes an unusually delayed production during the night of mimicries of sounds related to salient events. The fact

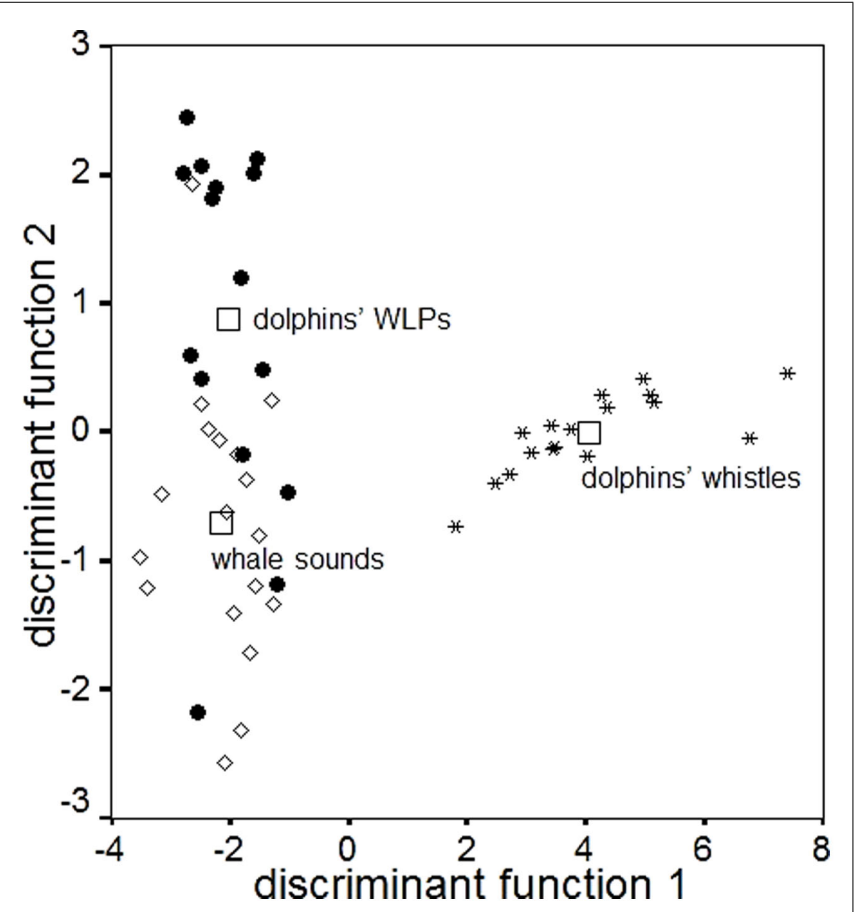

FIGURE 2 | Scatter plot of the discriminant function analysis comparing several acoustic parameters of dolphins' whistles (asterisks), dolphins' WLPs (black dots), and humpback whale sounds

(white diamonds). Squares indicate the group means. Discriminant function 1 corresponds to minimum frequency (canonical correlation coefficient $=0.949$; Wilks $-\lambda=0.069 ; P \leq 0.001$ ); discriminant function 2 corresponds to number of harmonics (canonical correlation coefficient $=0.551$; Wilks $-\lambda=0.696 ; P=0.001$ ). that these mimicries are produced when the dolphins are resting or sleeping and never when they were active is intriguing, especially as these sounds were only broadcast in the context of daytime shows. Hooper et al. (2006) show that mimicries are enhanced by association of sounds with objects or events, and that dolphins tend to produce these sounds in the corresponding contexts/activities. Therefore this raises the question of whether these night productions correspond to a form of "rehearsal" of daily shows. None of these vocalizations had ever been recorded before this broadcast was performed and information of the dolphins' life history clearly established that these animals had never had the opportunity to hear whale sounds previously. These mimicries occurred neither in direct association with the event, nor during interactions with humans and other dolphins. Data concerning both objective measurements of sound parameters and evaluations by humans converge to show that these atypical vocalizations were mimicries of the whale sounds broadcast during shows. Dolphins transposed frequencies as do killer whales (Foote et al., 2006) and a variety of mimicking birds (songbirds: Hausberger et al., 1991; parrots: Cruickshank et al., 1993). There may be some physical constraints, as the preferred range of frequencies for dolphin copying seems to be between 5 and $10 \mathrm{kHz}$ (Richards et al., 1984). Other authors give examples of low-pitched vocalizations emitted by dolphins (dos Santos et al., 1995; Connor and Smolker, 1996; van der Woude, 2009) and the question of whether these sounds correspond to mimicries has been raised (van der Woude, 2009). The sounds produced here clearly differ from these examples in their acoustic structure: WLPs are longer in duration and present more frequency modulations than do "brays" (dos Santos et al., 1995) and "pops" (Connor and Smolker, 1996), and their minimum and maximum frequencies are higher than those of "moans" (van der Woude, 2009). They also differ from other parts of the dolphin's species specific repertoire (reviewed in Janik, 2009).

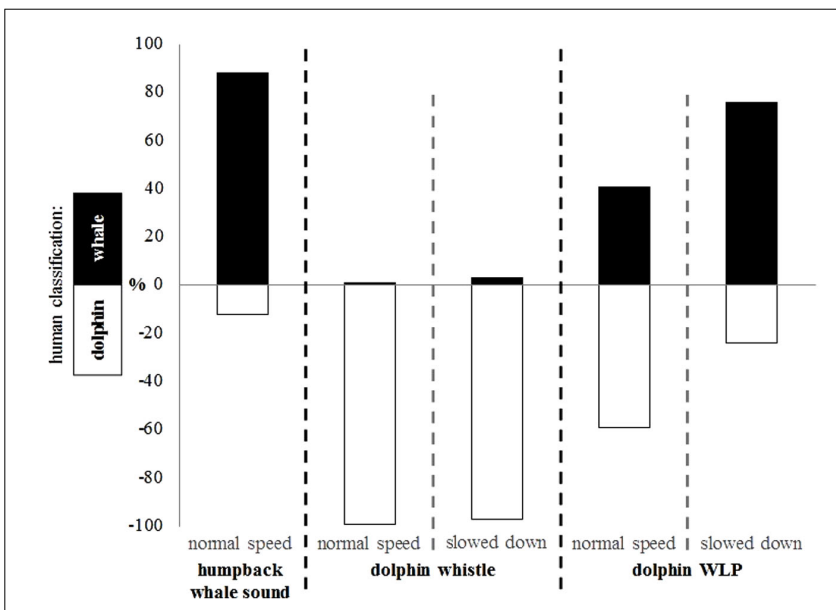

FIGURE 3 | Human evaluation of humpback whale sounds, dolphin whistles, and dolphin WLPs broadcast at different speeds. The classification is given in percent. The upper part (black) represents the classification of sounds as being produced by a whale; the lower part (white) represents the classification of sounds as being produced by a dolphin. 
These mimicries are a further proof that dolphins can learn when adult, as they heard this tape only when adult. The most remarkable aspect though is the delayed production of these mimicries in a quiet context. The "salience" of the event/interaction may have been crucial (Tyack and Sayigh, 1997; Hooper et al., 2006). These atypical vocalizations might be episodes of "vocal play" while at rest (Pepperberg, 2002; Kuczaj and Makecha, 2008), or, given the context, a potential part of a global rehearsal of these salient daytime events. The mimicries occurred only at quiet times, mostly during the night ( 0 to 3 a.m.), and outside any kind of social interactions, while obviously resting or sleeping. In captivity, show periods are salient events associated with multisensory stimulations (food reinforcement, vocal orders, public responses...). In addition to the general background (crowd, noise,...) that may be emotionally salient, food reinforcement used by trainers may increase excitation (Innes and McBride, 2008) and long term memories (Sankey et al., 2010); positive as well as negative-emotional valences could potentially induce increased mimicry and strong memories (Armstrong, 1960).

This is to our knowledge the first time that a long separation between hearing an auditory model and copying it has been observed in a marine mammal. One hypothesis predicts that dolphins, like parrots or songbirds, "practice" outside the "model's" presence (Hausberger et al., 1991). Another hypothesis predicts that these events correspond to rehearsals of a more global memory, as for example in the form of dreams during sleep or "day dreaming" in humans and animals (Cipolli et al., 2004). Reports of potential "dreaming" remain anecdotal in species other than laboratory animals. A pilot study by Lubrano Lavadera (2005) reported that young horses produced adult vocalizations (that they never produced during the day) during REM (i.e., rapid eye movement) sleep. This question is especially intriguing as cetaceans seem to lack typical REM sleep, or may have very short bouts of it (Mukhametov, 1995; Shpak et al., 2009). Nevertheless periods of sleep, mostly between 0 and 3 a.m., but also at times during the day, have been described, when the animals are floating or swimming slowly (Sekiguchi and Kohshima, 2003; Lyamin et al., 2008). Resting periods are associated with lower whistle production rates (Sekiguchi and Kohshima, 2003). Muscle jerks recalling

\section{REFERENCES}

Aly, M., and Moscovitch, M. (2010). The effects of sleep on episodic memory in older and younger adults. Memory 18, 327-334.

Armstrong, E. A. (1960). A Study of Bird Song. London: Oxford University Press.

Cipolli, C., Fagioli, I., Mazzetti, M., and Tuozzi, G. (2004). Incorporation of presleep stimuli into dream contents: evidence for a consolidation effect on declarative knowledge during REM sleep? J. Sleep Res. 13, 317-326.

Connor, R. C., and Smolker, R. A. (1996). 'Pop' goes the dolphin: a vocalization male bottlenose dolphins produce during consortships. Behaviour 133, 643-662.

REM sleep have been observed (Lyamin et al., 2008). Whether or not dolphins experience any kind of rehearsal of daytime events during their sleep therefore remains a mystery, although anecdotal reports by trainers suggest that dolphins perform a trained task better in the morning. Improvement of performance is a proved consequence of the rehearsal of memories in human dreams (Aly and Moscovitch, 2010).

As individuals and precise behavior could not be identified in this study, only further investigations associating EEG (electroencephalography) recordings, could confirm or infirm our hypothesis that these productions reflect rehearsal of daytime events by dolphins during rest or sleep. Their rarity ( $1.1 \%$ of total production) and timing (mostly at night) may explain that this constitutes the first report of mimicries of sounds heard during special events produced by dolphins in a resting/sleeping context. This finding opens very large perspectives for future investigations on dolphin learning processes and "mental representations."

\section{ACKNOWLEDGMENTS}

We thank the management of Planète Sauvage and the trainer staff of the Cité Marine for their cooperation as well as Françoise Joubaud and Jean-Pierre Richard for logistic support. Thank you to Carol Sankey and Ann Cloarec for correcting the English. This study was funded by ANR "ORILANG" and IUF.

\section{SUPPLEMENTARY MATERIAL}

The Supplementary Material for this article can be found online at http://www.frontiersin.org/comparative_psychology/10.3389/ fpsyg.2011.00386/abstract

Audio S1 | Example 1 of a Planète Sauvage dolphins' WLP ("whale-like" production).

Audio S2 | Example 1 of a Planète Sauvage dolphins' WLP slowed down (factor of 0.5$)$.

Audio S3 | Example 2 of a Planète Sauvage dolphins' WLP.

Audio S4 | Example 2 of a Planète Sauvage dolphins' WLP slowed down (factor of 0.5$)$.

Mammals, eds R. A. Kastelein, J. A. Thomas, and P. E. Nachtigall (Woerden: De Spil Publishers), 325-334.

Foote, A. D., Griffin, R. M., Howitt, D., Larsson, L., Miller, P. J. O., and Hoelzel, A. R. (2006). Killer whales are capable of vocal learning. Biol. Lett. 2, 509-512.

Frith, C. B., and Frith, D. W. (2004). The Bowerbirds. London: Oxford University Press.

Hausberger, M., Jenkins, P. F., and Keene, J. (1991). Species-specificity and mimicry in bird song: are they paradoxes? A reevaluation of song mimicry in the European starling. Behaviour 117, 53-82.

Hooper, S., Reiss, D., Carter, M., and McCowan, B. (2006). Importance of contextual saliency on vocal imitation by bottlenose dolphins. Int. J. Comp. Psychol. 19, 116-128.

Innes, L., and McBride, S. (2008). Negative versus positive reinforcement: an evaluation of training strategies for rehabilitated horses. Appl. Anim. Behav. Sci. 112, 357-368.

Janik, V. M. (2009). "Acoustic communication in delphinids," in Advances in the Study of Behaviour, Vol. 40, eds M. Naguib and V. M. Janik (Burlington: Academic Press), 123-157.

Jouvet, M. (1979). What does a cat dream about? Trends Neurosci. 2, 280-282.

Kelley, L. A., and Healy, S. D. (2011). Vocal mimicry. Curr. Biol. 21, R9R10. 
Kuczaj, S. A., and Makecha, R. (2008). "The role of play evolution and ontogeny of contextually flexible communication," in Evolution of Communicative Flexibility. Complexity, Creativity, and Adaptability in Human and Animal Communication, eds D. K. Oller and U. Griebel (Cambridge: MIT Press), 253-277.

Lubrano Lavadera, J. (2005). Etude qualitative des vocalises émises en phase de sommeil paradoxal chez le cheval de Przewalski (Equus ferus przewal$s k i)$. Thesis, Ministère de l'Education Nationale, de la Recherche et la Technologie; Ecole pratique des Hautes Etudes, Paris.

Lyamin, O. I., Manger, P. R., Ridgway, S. H., Mukhametov, L. M., and Siegel, J. M. (2008). Cetacean sleep: an unusual form of mammalian sleep. Neurosci. Biobehav. Rev. 32, 1451-1484.

May-Collado, L. J. (2010). Changes in whistle structure of two dolphin species during interspecific associations. Ethology 116, 1065-1074.

Mukhametov, L. M. (1995). Paradoxical sleep peculiarities in aquatic mammals. Sleep Res. 24A, 202.

Pepperberg, I. M. (1997). "Social influences on the acquisition of humanbased codes in parrots and nonhuman primates," in Social Influences on Vocal Development, eds C. T.
Snowdon and M. Hausberger (Cambridge: University Press), 157-177.

Pepperberg, I. M. (2002). The Alex Studies: Cognitive and Communicative Abilities of Grey Parrots. Cambridge: Harvard University Press.

Poole, J. H., Tyack, P. L., StoegerHorwath, A. S., and Watwood, S. (2005). Elephants are capable of vocal learning. Nature 434, 455-456.

Reiss, D., and McCowan, B. (1993). Spontaneous vocal mimicry and production by bottlenose dolphins (Tursiops truncatus): evidence from vocal learning. J. Comp. Psychol. 107, 301-312.

Revonsuo, A. (2000). The reinterpretation of dreams: an evolutionary hypothesis of the function of dreaming. Behav. Brain Sci. 23, 793-1121.

Richards, D. G., Wolz, J. P., and Herman, L. M. (1984). Vocal mimicry of computer generated sounds and vocal labeling of objects by a bottlenosed dolphin, Tursiops truncatus. J. Comp. Psychol. 98, 10-28.

Ruckebusch, Y., Barbey, P., and Guillemot, P. (1970). Les états de sommeil chez le cheval (Equus caballus). C. R. Seances Soc. Biol. 164, 658-665.

Sankey, C., Richard-Yris, M.-A., Leroy, H., Henry, S., and Hausberger, M. (2010). Training experience induces lasting memories of humans in horses, Equus caballus. Anim. Behav. 79, 869-875.

Sekiguchi, Y., and Kohshima, S. (2003). Resting behaviors of captive bottlenose dolphins (Tursiops truncatus). Physiol. Behav. 79, 643-653.

Shpak, O. V., Lyamin, O. I., Manger, P. R., Siegel, J. M., and Mukhametov, L. M. (2009). States of rest and activity in the Commerson's dolphin Cephalorhynchus commersonii. J. Evol. Biochem. Physiol. 45, 111-119.

Stickgold, R., Hobson, J. R., and Fosse, M. (2001). Sleep, learning, and dreams: off-line memory reprocessing. Science 294, 1052-1057.

Thorpe, W. H. (1961). Bird-Song: The Biology of Vocal Communication and Expression in Birds. Oxford: Oxford University Press.

Tyack, P. L., and Sayigh, L. S. (1997) "Vocal learning in cetaceans," in Social Influences on Vocal Development, eds C. T. Snowdon and M. Hausberger (Cambridge: University Press), 208-233.

van der Woude, S. E. (2009). Bottlenose dolphins (Tursiops truncatus) moan as low in frequency as baleen whales. J. Acoust. Soc. Am. 126, 1552-1562.

Vandekerckhove, M., and Cluydts, R. (2010). The emotional brain and sleep: an intimate relationship. Sleep Med. Rev. 14, 219-226.
Wich, S. A., Swartz, K. B., Hardus, M. E., Lameira, A. R., Stromberg, E., and Shumaker, R. W. (2009). A case of spontaneous acquisition of a human sound by an orangutan. Primates 50, 56-64.

Conflict of Interest Statement: The authors declare that the research was conducted in the absence of any commercial or financial relationships that could be construed as a potential conflict of interest.

Received: 04 October 2011; accepted: 08 December 2011; published online: 29 December 2011.

Citation: Kremers D, Jaramillo $M B$, Böye $M$, Lemasson $A$ and Hausberger $M$ (2011) Do dolphins rehearse showstimuli when at rest? Delayed matching of auditory memory. Front. Psychology 2:386. doi: 10.3389/fpsyg.2011.00386 This article was submitted to Frontiers in Comparative Psychology, a specialty of Frontiers in Psychology.

Copyright (C) 2011 Kremers, Jaramillo, Böye, Lemasson and Hausberger. This is an open-access article distributed under the terms of the Creative Commons Attribution Non Commercial License, which permits non-commercial use, distribution, and reproduction in other forums, provided the original authors and source are credited. 